\title{
Article/Artigo
}

\section{Evaluation of the histopathological hepatic lesions and opportunistic agents in Brazilian HIV patients}

\author{
Avaliação das alterações histológicas hepáticas e infecções oportunistas em pacientes brasileiros \\ infectados pelo HIV
}

Graziella Hanna Pereira ${ }^{1}$, Diva Carvalho Collarile Yamagutti ${ }^{2}$ and João Silva de Mendonça ${ }^{3}$

\begin{abstract}
Introduction: to evaluated the type histopathological hepatic lesions and opportunistic agents in Brazilian HIV-infected patients. Methods: we examined 52 percutaneous liver biopsies of $50 \mathrm{HIV}$-infected patients who had at least two of the following conditions: fever of unknown origin, unexplained severe emaciation, hepatomegaly or abnormal liver chemistry. The specimens were cultured for mycobacteria and fungi and stained by standard procedures. Results: reactive patterns, granulomatous hepatitis and chronic active hepatitis were verified in $28(54 \%), 11(21 \%)$ and $8(15 \%)$ of the patients respectively. Opportunistic infections were diagnosed in 18 (36\%) patients: mycobacteria in 12 (24\%), Cryptococcus neoformans in $5(10 \%)$ patients and mycobacteria and yeast was isolated from the same liver fragment in one patient. Conclusions: mycobacteriosis was the most common opportunistic infection and liver tissue culture is an important method to detect opportunistic agents, even in the absence of histological lesions.
\end{abstract}

Key-words: Liver biopsy. Mycobacteriosis. AIDS. Liver histology.

\section{RESUMO}

Introdução: avaliar os tipos de lesões histopatológicas e infecções oportunistas de Brasileiros infectados pelo HIV. Métodos: Foram analisadas 52 biópsias hepáticas percutâneas de 50 pacientes que apresentavam pelo menos duas das alterações: febre de origem indeterminada, emagrecimento inexplicado, hepatomegalia ou anormalidades na bioquímica hepática. $\mathrm{O}$ fragmento de tecido hepático foi submetido a histopatologia por métodos habituais e cultura para micobacteria e fungo. Resultados: padrão reacional, hepatite granulomatosa e hepatite crônica ativa foram encontrados em 28 (54\%), 11 (21\%) e 8 (15\%) dos pacientes respectivamente. Infecções oportunistas foram diagnosticadas em 18 (36\%) dos pacientes: micobacteria em 12 (24\%), Cryptococcus neoformans em 5 (10\%) pacientes e micobacteria e fungo foram isolados no mesmo fragmento em um paciente. Conclusões: micobacteriose foi a infecção oportunista mais comum e a cultura de tecido hepático foi um importante método para detecção de infecções, mesmo na ausência de lesões histológicas.

Palavras-chaves: Biópsia hepática. Micobacteriose. SIDA. Histologia hepática.

1. Department of Infectious Diseases and Infection Control, Hospital Brigadeiro, São Paulo, SP, Brazil. 2. Department of Pathology, Hospital Servidor Público Estadual, São Paulo, SP, Brazil. 3. Department of Infectious Diseases and Infection Control, Hospital Servidor Público Estadual, São Paulo, SP, Brazil.

Address to: Dra. Graziella Hanna Pereira. CCIH/Hospital Brigadeiro. Av. Jandira 79/231 Bloco A2, Moema, 04080-000 São Paulo, SP.

Tel: 5511 9915-8008/55 11 3170-6112

e-mail: ghpereira1@terra.com.br

Received in 05/08/2009 Accepted in 09/12/2009

\section{INTRODUCTION}

Research involving AIDS patients has determined a high prevalence of underlying hepatic abnormalities. The spectrum and prevalence of different diseases among patients with AIDS varies between countries ${ }^{1}$.

Hepatic manifestations can be a harbinger of disseminated opportunistic infections in AIDS patients ${ }^{2}$. Liver biopsy is a useful technique for the diagnosis of fever of unknown origin (FUO) in HIV-infected patients. Early biopsy should be considered in patients with hepatosplenomegaly and above-normal alkaline phosphatase levels ${ }^{3}$. Many liver and pancreatic lesions caused by opportunistic agents have been diagnosed based on autopsy results ${ }^{4}$.

Studies in underdeveloped countries suggest that hepatic tuberculosis is the most common liver disease in AIDS patients ${ }^{1}$, followed by Mycobacterium avium complex infection, cytomegalovirus, toxoplasmosis, fungal infections, malignant tumors ${ }^{5}$ and concomitant pathologies $^{2}$.

Few studies of liver complications in Brazilian patients have been conducted, some involving case reports of hepatic pathology secondary to opportunistic diseases in HIV-infected patients, associated with tuberculosis ${ }^{6}$, histoplasmosis ${ }^{7}$, and Salmonella-Schistosoma mansoni ${ }^{8}$. Histopathological exams of liver biopsies were not performed in these Brazilian AIDS studies.

We examined hepatic histopathological findings and the diagnosis of opportunistic agents in Brazilian HIV patients who were not yet on antiretroviral drug therapy. This situation is possible in countries without resources and in patients who have not been diagnosed or placed on HIV therapy. 


\section{METHODS}

The State Public Servants' Hospital (Hospital Servidor Público Estadual) is a public, tertiary care, teaching hospital that belongs to the Brazilian National Healthcare System (SUS). We analyzed 50 cases in which 52 percutaneous liver biopsy (PLB) had been performed. In two patients, the procedure was repeated due to clinical indications. Patients that presented at least two clinical or laboratory alterations including: prolonged fever, accentuated weight loss, hepatomegaly and liver function test abnormalities were selected for PLB. The following data was recorded for these patients: age, sex, alcohol abuse, use of medicines, as well as clinical symptoms, including fever, weight loss, hepatomegaly, signs of hepatic deficiency and abnormal laboratory parameters. Liver function test abnormalities were defined as above normal levels of serum transaminases, alanine aminotransferase (ALT) and aspartate aminotransferase (AST), alkaline phosphatase (Aph) and glutamic-transferase (Gt). The normal values considered were: ALT 5-35U/1, AST 8-40U/1, Aph 30-40U/1 and Gt up to 30U/1.

All percutaneous liver biopsies were performed with a Menghini needle, using standard techniques.

Unfixed tissue was cultivated for Mycobacterium and fungi. Formalin-fixed tissue sections were stained with hematoxylin and eosin, Masson's trichrome, Prussian blue, Gomori-methenamine silver, periodic acid-Schiff and Ziehl-Neelsen stains. Histology was analyzed by a single pathologist (DCCY). The Chi square and Fisher exact tests were used to compare categorical variables $(\alpha=0.05)$.

\section{RESULTS}

Among the 50 patients, 48 were male; median age was 35 years of age (range $16-60$ years-old). Nine (18\%) patients had alcohol abuse problems and $30 \%$ were illicit drug users.

Thirty (60\%) patients presented opportunist infections, five (10\%) had Kaposi's sarcoma, two (4\%) had Hodgkin's lymphoma and one (2\%) had idiopathic thrombocytopenic purpura. The clinical characteristics, laboratorial and histological findings of the patients are described in Table 1.

Liver biopsy showed histological alterations in $98 \%$ of the patients; the only patient who apparently had a normal liver (2\%) was infected with mycobacteria. Two patients were submitted to two biopsies each, once after the initial diagnosis of acute hepatitis and the other 10 months later, after the disease had evolved to chronic active hepatitis in one patient and two months later in a patient with nonspecific reactive hepatitis that had evolved to acute cholestatic hepatitis.

Nonspecific reactive hepatitis $(\mathrm{RH})$ involved hyperplasia and hypertrophy of the Kupffer cells (100\%), hepatocelular degeneration (76\%), inflammatory infiltration in the portal and periportal area $(70 \%)$ and lobular $(42 \%)$, sinusoidal dilatation (60\%) and focal steatosis (56\%) were observed in the liver biopsies. Granulomatous hepatitis $(\mathrm{GH})$ presented lobular and portal granulomas, rarely formed by Langhans' cells, with minimal central necrosis. Mycobacteria were verified in three patients and yeast in five patients with $\mathrm{RH}$. Among the 11 patients with $\mathrm{GH}$, nine presented opportunistic infections (eight mycobacteria and one yeast, Figure 1). In one patient, extensive portal inflammation with Hodgkin's lymphoma was verified, associated with granulomas, with no infectious agents.
TABLE 1 - Description of the clinical characteristics, laboratory test results and histological findings of Brazilian HIV patients with liver problems.

\begin{tabular}{|c|c|c|c|}
\hline \multirow[b]{2}{*}{ Characteristics } & \multicolumn{2}{|c|}{ Patients } & \multirow[b]{2}{*}{ Mean (range) } \\
\hline & $\mathrm{n}$ & $\%$ & \\
\hline \multicolumn{4}{|l|}{ Clinical } \\
\hline fever & 26 & 52.0 & \\
\hline weight loss & 35 & 70.0 & \\
\hline hepatomegaly & 33 & 66.0 & \\
\hline splenomegaly & 17 & 34.0 & \\
\hline \multicolumn{4}{|l|}{ Laboratory findings } \\
\hline alanine aminotransferase (ALT) & 33 & 66.0 & $114(36-700)$ \\
\hline aspartate aminotransferase (AST) & 32 & 65.0 & $129(51-791)$ \\
\hline alkaline phosphatase (Aph) & 23 & 50.0 & $277(46-1620)$ \\
\hline glutamic-transferase (Gt) & 44 & 94.0 & $264(31-1845)$ \\
\hline \multicolumn{4}{|l|}{ Histological findings } \\
\hline non-specific reactive hepatitis $(\mathrm{RH})$ & 28 & 54.0 & \\
\hline granulomatous hepatitis $(\mathrm{GH})$ & 11 & 21.0 & \\
\hline chronic active hepatitis (CAH) & 8 & 15.0 & \\
\hline acute hepatitis $(\mathrm{AcH})$ & 2 & 4.0 & \\
\hline alcoholic hepatitis $(\mathrm{AlH})$ & 2 & 2.0 & \\
\hline normal liver (NL) & 1 & 2.0 & \\
\hline \multicolumn{4}{|l|}{ Opportunistic liver infection findings } \\
\hline tuberculosis & 12 & 24.0 & \\
\hline cryptococcus & 5 & 10.0 & \\
\hline tuberculosis and cryptococcus & 1 & 2.0 & \\
\hline
\end{tabular}
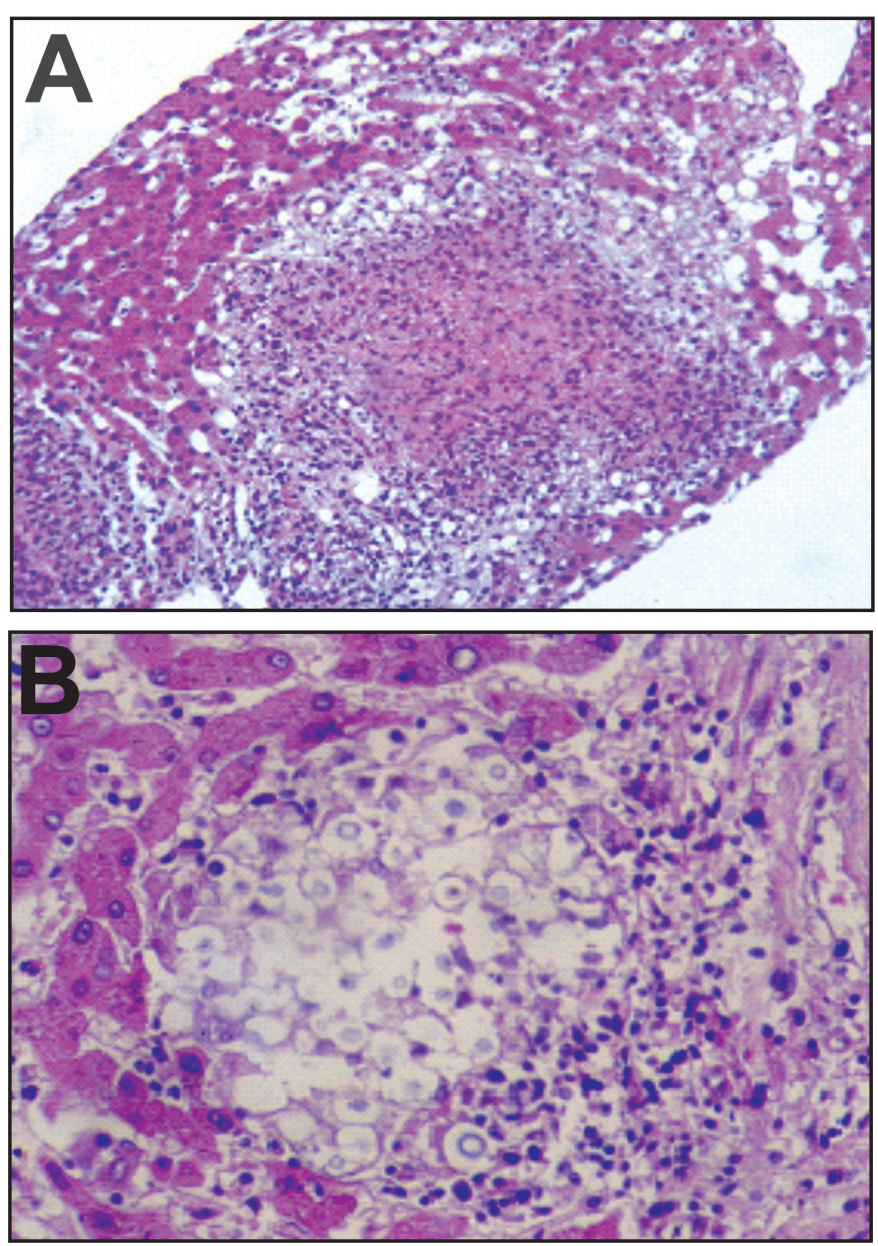

Figure 1 - A: Granulomatous hepatitis of tuberculosis (HE stain $x$ 100): B Cryptococcus neoformans in a granuloma in the liver parenchyma (HE stain $\mathrm{x} 400$ ). 
Mycobacteria were observed in 13 liver biopsies and yeast in six (five Cryptococcus neoformans and one unidentified yeast). One patient presented Cryptococcus and Mycobacteria in the same liver fragment. Liver biopsy permitted the diagnosis of opportunistic infections in nine (18\%) patients, these included eight with mycobacteriosis and one with Cryptococcus infection.

The clinical alterations were not significantly correlated with the presence of opportunisticinfections. Alkaline phosphatase was significantly altered in liver granuloma tissue. Levels of other liver enzymes, such as AST, ALT and Gt, were not correlated with histological findings. There was a significant relation between $\mathrm{GH}$ and opportunistic infections, specifically those caused by Mycobacteria. There was no correlation between histological findings and fungus infection (Table 2).

Among the 13 patients with a diagnosis of Mycobacteria, Ziehl-Neelsen staining was positive in six out of 12 (50\%) patients, cultures were positive in all nine patients tested; Mycobacterium tuberculosis was identified in four of these. Due to a lack of hepatic tissue, histopathology was not performed for one patient and no cultures were made from samples of four patients. Among the patients diagnosed with fungi, two out of six were determined by staining and four out of five by specific culture.

TABLE 2- Correlation of clinical, laboratory and opportunistic findings with histological findings.

\begin{tabular}{|c|c|c|c|c|c|c|c|c|c|}
\hline \multirow{2}{*}{$\begin{array}{l}\text { Clinical/ } \\
\text { laboratoryfindings }\end{array}$} & \multicolumn{2}{|c|}{ RH } & \multicolumn{2}{|c|}{$\mathrm{GH}$} & \multicolumn{2}{|c|}{$\mathrm{CAH}$} & \multicolumn{2}{|c|}{ Normal } & \\
\hline & $\mathrm{n}$ & $\%$ & $\mathrm{n}$ & $\%$ & $\mathrm{n}$ & $\%$ & $\mathrm{n}$ & $\%$ & \\
\hline Fever & 15 & 54 & 8 & 73 & - & - & - & - & 0.27 \\
\hline Hepatomegaly & 8 & 73 & 17 & 61 & - & - & - & - & 0.51 \\
\hline Weight loss & 7 & 64 & 19 & 68 & - & - & - & - & 0.8 \\
\hline AST & 16 & 57 & 8 & 73 & 6 & 75 & - & - & 0.5 \\
\hline ALT & 17 & 61 & 6 & 55 & 4 & 50 & - & - & 0.8 \\
\hline Gt & 24 & 86 & 10 & 100 & 5 & 71 & - & - & 0.22 \\
\hline Aph & 11 & 27 & 9 & 90 & 2 & 29 & - & - & 0.013 \\
\hline Mycobacteria & 3 & 11 & 8 & 73 & 1 & 12.5 & 1 & - & $0<0.01$ \\
\hline Fungi & 5 & 18 & 1 & 9 & 0 & 0 & 0 & - & 0.12 \\
\hline Opportunistic infection & s 8 & 28.5 & 9 & 82 & 1 & 12.5 & - & - & $0<0.01$ \\
\hline
\end{tabular}

RH: non-specific reactive hepatitis, $\mathrm{GH}$ : granulomatous hepatitis, $\mathrm{CAH}$ : chronic active hepatitis, AST: aspartate aminotransferase, ALT: alanine aminotransferase, Gt: glutamic-transferase, Aph: alkaline phosphatase.

\section{DISCUSSION}

Hepatic histological abnormalities were observed in all the patients; this frequency was higher than reported in other studies. Lanjewar et al ${ }^{1}$ reported $58 \%$ patients with significant pathological lesions; the most common pathological processes involving the liver appeared to be secondary to infections ${ }^{1}$. These findings could be explained by the phase of illness in these patients, with opportunistic disease occurring in $76 \%$, along with drug abuse and frequent use of medicines.

Opportunistic infections were diagnosed in $36 \%$ of the patients, half of these by liver biopsy. Altered alkaline phosphatase levels were related to granulomatous hepatitis and mycobacteria infection. Garcia-Ordonez et al ${ }^{3}$ studied 58 HIV-infected patients who underwent PLB for evaluation of FUO in Spain. The diagnosis was established in 51 (87.9\%) patients; tuberculosis (50\%) and leishmaniasis $(20.7 \%)$ were the most common. PLB was diagnostic in $25(43.1 \%)$ cases, helpful in $13(22.4 \%)$, and normal or nonspecific in the remaining 20 (34.5\%); they concluded that PLB is a useful technique for the diagnosis of FUO in HIV-infected persons and that early PLB should be considered in patients with hepatosplenomegaly and increased alkaline phosphatase levels ${ }^{3}$. Other studies have reported similar conclusions ${ }^{2,9}$.

Echejoh et al ${ }^{10}$ evaluated postmortem hepatic histopathological findings in HIV patients in Nigeria; most (65\%) patients had clinical tuberculosis. Granulomatous hepatitis, chronic hepatitis, nonspecific reactive hepatitis and steatosis were the most common hepatic histopathological lesions, occurring in $34,20,15$ and $12 \%$ of patients, respectively. Seven percent had normal histological features ${ }^{10}$.

In our study, the histopathological findings were often nonspecific. A correlation was determined between granulomatous hepatitis and opportunistic hepatic infections, with prevalence of Mycobacterium tuberculosis, and Cryptococcus neoformans among the fungi. Culture for mycobacteriosis and of the deep mycoses was an important approach for the detection of opportunists, even when Ziehl-Neelsen and PAS staining of the liver was negative.

In conclusion, Mycobacteriosis was the most prevalent hepatic infection in Brazilian patients and culture of liver fragments is important for the diagnosis of opportunistic infection.

\section{ACKNOWLEDGMENTS}

We would like to thank Maria de Fátima Beu for preparing the cultures of the hepatic fragments.

\section{CONFLICT OF INTEREST}

The authors declare that there is no conflict of interest.

\section{REFERENCES}

1. Lanjewar DN, Rao RJ, Kulkarni SB, Hira SK. Hepatic pathology in AIDS: a pathological study from Mumbai, India. HIV Medicine 2004;5:253-257.

2. Chang YG, Chen PJ, Hung CC, Chen MY, Lai MY, Chen DS. Opportunistic hepatic infections in AIDS patients with fever of unknown origin. Journal of the Formosan Medical Association 1999;98:5-10.

3. Garcia-Ordonez MA, Colmenero JD, Jimenez-Onate F, Martos F, Martinez J, Juarez C. Diagnostic usefulness of percutaneous liver biopsy in HIV-infected patients with fever of unknown origin. Journal of Infection 1999;38:94-98.

4. Danesi G, Pianta P, Mastroianni A, Cicognani C, Cristoni L, Sama C. Hepatic and pancreatic disease in patients with acquired immunodeficiency syndrome (AIDS). Minerva Medica 1999;90:123-131.

5. Shakhgil'dian VI., Kravchenko AV, Parkhomenko Iu G, Tishkevich OA, Serova VV, Gruzdev B M. Liver involvement in secondary infections in HIV-infected patients. Terapevticheskiî Arkhiv 2002;74:40-43.

6. Barone B, Kreuzig PL,Gusmão PM, Chamie D, Bezerra S, Pinheiro P, et al. Case report of lymph nodal, hepatic and splenic tuberculosis in an HIV-positive patient. Brazilian Journal Infectious Disease 2006;10:149-153.

7. Borges AS, Ferreira MS, Silvestre MT, Nishioka SA, Rocha A. Histoplasmosis in immunodepressed patients: study of 18 cases seen in Uberlandia, MG. Revista da Sociedade Brasileira de Medicina Tropical 1997;30:119-124.

8. LambertucciJR, Rayes AA, Gerspacher-Lara R. Salmonella-S.mansoni association in patients with acquired immunodeficiency syndrome. Revista do Instituto de Medicina Tropical de São Paulo 1998;40:233-235.

9. Piratvisuth T, Siripaitoon P, Sriplug H, Ovartlarnporn B. Findings and benefit of liver biopsies in 46 patients infected with human immunodeficiency virus. Journal of Gastroenterology and Hepatology 1999;14:146-149.

10. Echejoh GO, Mandong BM, Tanko MN, Manasseh AN, Okeke EN, Agaba E I Hepatic histopathological findings in HIV patients at postmortem in Jos university teaching hospital, Nigeria. Tropical Doctor 2006;36:228-231. 